$8-25-2009$

\title{
On TGO Creep and the Initiation of a Class of Fatigue Cracks in Thermal Barrier Coatings
}

\author{
Mercedes T. Hernandez \\ Anette M. Karlsson \\ Cleveland State University, a.karlsson@csuohio.edu \\ Marion Bartsch \\ German Aerospace Center
}

Follow this and additional works at: https://engagedscholarship.csuohio.edu/enme_facpub

Part of the Mechanical Engineering Commons

How does access to this work benefit you? Let us know!

\section{Publisher's Statement}

NOTICE: this is the author's version of a work that was accepted for publication in Surface and Coatings Technology. Changes resulting from the publishing process, such as peer review, editing, corrections, structural formatting, and other quality control mechanisms may not be reflected in this document. Changes may have been made to this work since it was submitted for publication. A definitive version was subsequently published in Surface and Coatings Technology, 203, 23, (08-25-2009); 10.1016/j.surfcoat.2009.05.018

\section{Original Citation}

Hernandez, M. T., Karlsson, A. M., and Bartsch, M., 2009, "On TGO Creep and the Initiation of a Class of Fatigue Cracks in Thermal Barrier Coatings," Surface \& Coatings Technology, 203(23) pp. 3549-3558.

This Article is brought to you for free and open access by the Mechanical Engineering Department at EngagedScholarship@CSU. It has been accepted for inclusion in Mechanical Engineering Faculty Publications by an authorized administrator of EngagedScholarship@CSU. For more information, please contact library.es@csuohio.edu. 


\title{
On TGO creep and the initiation of a class of fatigue cracks in thermal barrier coatings
}

\author{
Mercedes T. Hernandez ${ }^{\text {a }}$, Anette M. Karlsson ${ }^{\text {a,* }}$, Marion Bartsch ${ }^{\text {b }}$ \\ a Department of Mechanical Engineering, University of Delaware, Newark, DE, 19716, USA \\ ${ }^{b}$ Institute of Materials Research, German Aerospace Center (DLR), Linder Hoehe, D-51147 Cologne, Germany
}

\section{Introduction}

A common method to increase the performance of gas turbine engines is to deposit thermal barrier coatings (TBCs) on the high temperature components. TBCs can potentially increase both the durability and the fuel efficiency of the gas turbine [1,2]. Even though significant advances have been made in the last decade, TBCs still fail prematurely and the design engineers cannot take full advantage of them [2]. The premature failures are due to a lack of understanding of the TBC failure mechanisms: the failures are governed by the complicated multilayered structure of TBCs that evolves during use. The layers include an intermetallic bond coat that is deposited on the superalloy, and a ceramic top coat that is deposited on the bond coat (Fig. 1). The top coat provides thermal insulation whereas the bond coat provides oxidation protection to the superalloy substrate. The oxidization protection is manifested by the bond coat providing aluminum to form an aluminum oxide $\left(\mathrm{Al}_{2} \mathrm{O}_{3}\right)$ scale between the bond coat and the top coat during high temperature exposure. The oxide scale is commonly referred to as the thermally grown oxide (TGO). Even though the TGO is relatively thin (typically less than $8 \mu \mathrm{m}$ at failure) compared to the other TBC constituents, the majority of TBC failures are associated with the TGO. More specifically, failure of TBCs commonly occurs at the bond coat/TGO interface or in the TGO/top coat interface [3].

For the TBC investigated (a NiCoCrAlY bond coat and a zirconia top coat stabilized by 6-7 wt.\% yttria, which were deposited by electron beam-physical vapor deposition, EB-PVD), two TGO layers are observed: a mixed zone adjacent to the top coat and a continuous and mostly $\alpha$ -

\footnotetext{
* Corresponding author, Fax: +1 3028313619.

E-mail address: karlsson@udel.edu (A.M. Karisson).
}

alumina layer adjacent to the bond coat, Fig. 1. Braue et al. [4] observed these zones in EB-PVD coating-systems with NiCoCrAlY bond coats. The fine-grained mixed zone is composed of zirconia particles embedded in an alumina matrix. Schulz et al. [5] investigated the formation of the TGO for this class of TBC. They found that the thickness of the mixed zone increases during thermal exposure until a critical thickness is achieved. During thermal exposure, a continuous layer of $\alpha$-alumina forms and grows underneath the mixed zone on top of the bond coat. The thickness of the TGO depends on the temperature during thermal exposure and the time at temperature.

In addition to TGO growth, TBCs subjected to high temperatures exhibit time and temperature dependent materials evolution. This includes sintering, interdiffusion, precipitating and dissolution of phases, along with chemical reactions in the respective TBC constituents. Moreover, TBCs are subjected to both thermal and mechanical cyclic loading during operation. Consequently, failures of TBCs are due to a complicated non-linear coupling between thermomechanical cyclic loading and materials evolution caused by timedependent mechanisms. When investigating failures and establishing life-prediction models, it is important to capture these behaviors correctly and in a time economic manner [6]. Due to the non-linear coupling between thermo-mechanical loading and materials evolution, accelerated test methods often produce results that are difficult to translate to real service conditions. However, work is ongoing in our research laboratories to develop such accelerated test methods.

An interesting failure mode observed in specimens subjected to a proposed accelerated test scheme $[7,8]$ will be considered in this work. We believe that by understanding the evolution of this failure mode, significant insight into the non-linear coupling between thermomechanical cyclic loading and materials evolution due to timedependent mechanisms may be obtained. In the case of interest, the 


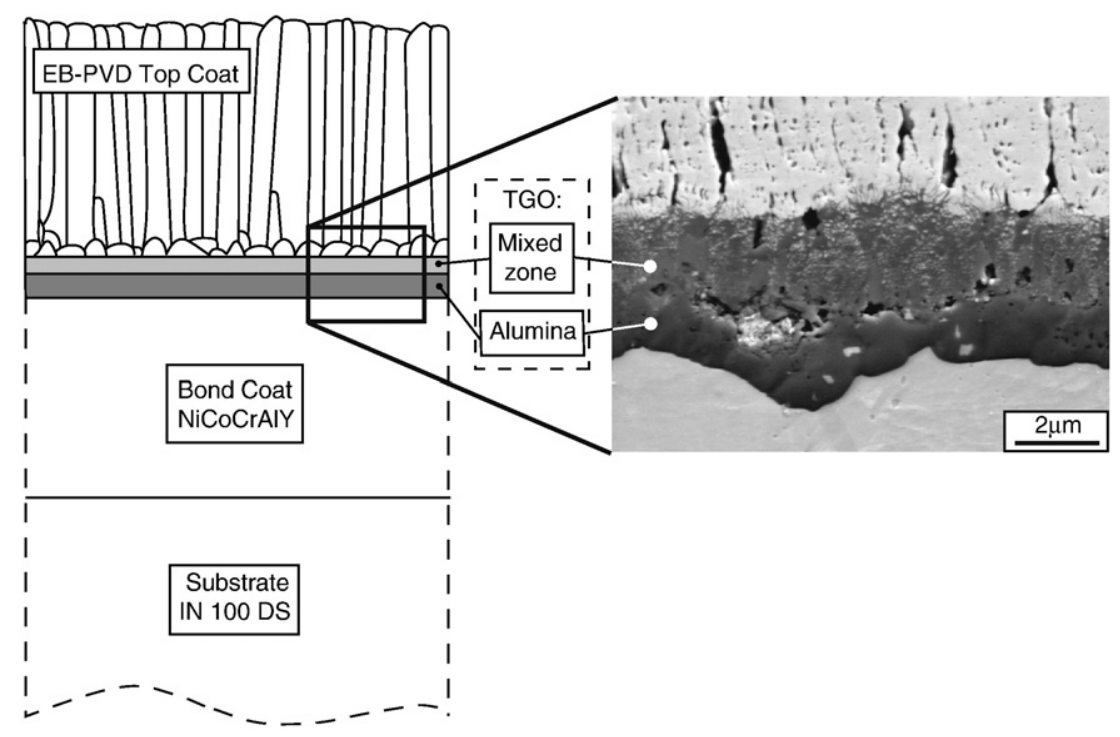

Fig. 1. Schematic and SEM image of the TBC, including the mixed zone and alumina layer of the TGO.

specimens were pre-oxidized before being subjected to thermomechanical cyclic testing [7]. After testing, distinct crack formations were observed throughout the specimens. These formations were characterized by a crack extending through the thickness of the top coat and the TGO, and into the bond coat. In the bond coat, the cracks kink and propagate perpendicular and close to the interface between the TGO and the bond coat [6-8].

The purpose of this study is to investigate how these cracks initiate. This will reveal important information about the properties of the TBC system, in particular of the TGO. The outline of the paper is as follows: in Section 2 the experimental technique is reviewed, along with the results of interest for the current investigation. A hypothesis for the crack initiation is developed in Section 3. To quantify the hypothesis, a numerical model based on finite element simulations is developed in Section 4 and the results of the numerical simulations are presented in Section 5. Our results suggest that the cracks are initiated through a non-linear coupling between TGO growth, TGO creep, and the thermo-mechanical cyclic loading.

\section{Experiments}

The experiments and the results have been reported in previous studies [6-9]. For clarity of the discussion that follows, we will here give a brief outline of the test method and review selected results pertaining to the current work.

\subsection{Accelerated testing}

The specimens were processed at the German Aerospace Center (DLR). The TBC was deposited on hollow dog-bone shaped specimens with a circular cross section. The bond and top coats were deposited by electron beam-physical vapor deposition (EB-PVD). The materials used and their dimensions are summarized in Table 1 . The nominal

Table 1

Materials and dimensions of the experimental specimens. [7].

\begin{tabular}{lll}
\hline Layer & Material & Thickness \\
\hline Substrate & IN100 DS & $2 \mathrm{~mm}$ \\
Bond Coat & NiCoCrAlY & $120 \mu \mathrm{m}$ \\
Top coat & Yttria partially stabilized (7-8 wt.\%) & $220 \mu \mathrm{m}$ \\
As-coated TGO & Mixed zone & $0.3 \mu \mathrm{m}$ \\
Aged TGO & Mixed zone and alumina layer & $5 \mu \mathrm{m}$ \\
\hline
\end{tabular}

The TGO thickness corresponds to initial thickness. inner and outer diameter was 4 and $8.6 \mathrm{~mm}$, respectively. A $0.3 \mu \mathrm{m}$ thick TGO formed during the coating procedure [7].

The accelerated testing scheme consists of two steps: (1) pre-heat treatment of the specimens in a furnace, and (2) thermo-mechanical fatigue testing.

Selected specimens were pre-heat treated to generate a thicker TGO. The pre-heat treatment was cyclic and was performed in a separate furnace: Each cycle consists of $24 \mathrm{~h}$ at high temperature $\left(1000{ }^{\circ} \mathrm{C}\right)$, accumulating either 250 or $500 \mathrm{~h}$ at high temperature. Every $24 \mathrm{~h}$ the specimens were cooled down to ambient temperature by removing them from the furnace. A $5 \mu \mathrm{m}$ thick TGO formed during the pre-heat treatment for specimens subjected to high temperature for $500 \mathrm{~h}$. This thickness has been observed in turbine blades after service [8].

After pre-heat treatment, the specimens were subjected to thermo-mechanical testing via thermal gradient mechanical fatigue (TGMF) testing, developed at DLR. This test set-up allows testing and evaluation of TBCs by simulating the conditions in an aircraft engine in an accelerated manner [9]. The loading sequence consists of heating to high temperature, hold at high temperature, and cool to low temperature. The thermal cycling is synchronized with an applied cyclic axial force. The specimen is heated from the outside and cooled from the inside, and the mechanical loading is imposed by a servohydraulic testing machine. The outer surface of the specimen is heated by the radiation of four quartz lamps, which are focused onto the specimen by elliptical mirrors. The specimen is cooled internally by a controlled air flow. This creates a temperature gradient over the specimen's wall, similar to that of a gas turbine blade. During cooling, the specimen is cooled with cold air blown onto the surface, and the axial force is removed. The temperature and axial force are varied as indicated in Fig. 2A, where the maximum temperature and nominally applied axial stress was $1000{ }^{\circ} \mathrm{C}$ and $100 \mathrm{MPa}$, respectively.

For comparison, selected specimens without pre-heat treatment were subjected to the TGMF test described above. These specimens are thus tested in as-coated conditions.

\subsection{Selected experiments and observations}

The specimens with preceding heat treatment (aged specimens) revealed distinct defects after the TGMF test, Fig. 3. The observed defects

${ }^{1}$ The applied nominal stress of $100 \mathrm{MPa}$ was selected to represent a stress level similar to what an aero-engine may experience and to ensure that the substrate fail after about 10,000 to 20,000 cycles; approximately the lifetime of a turbine blade. 

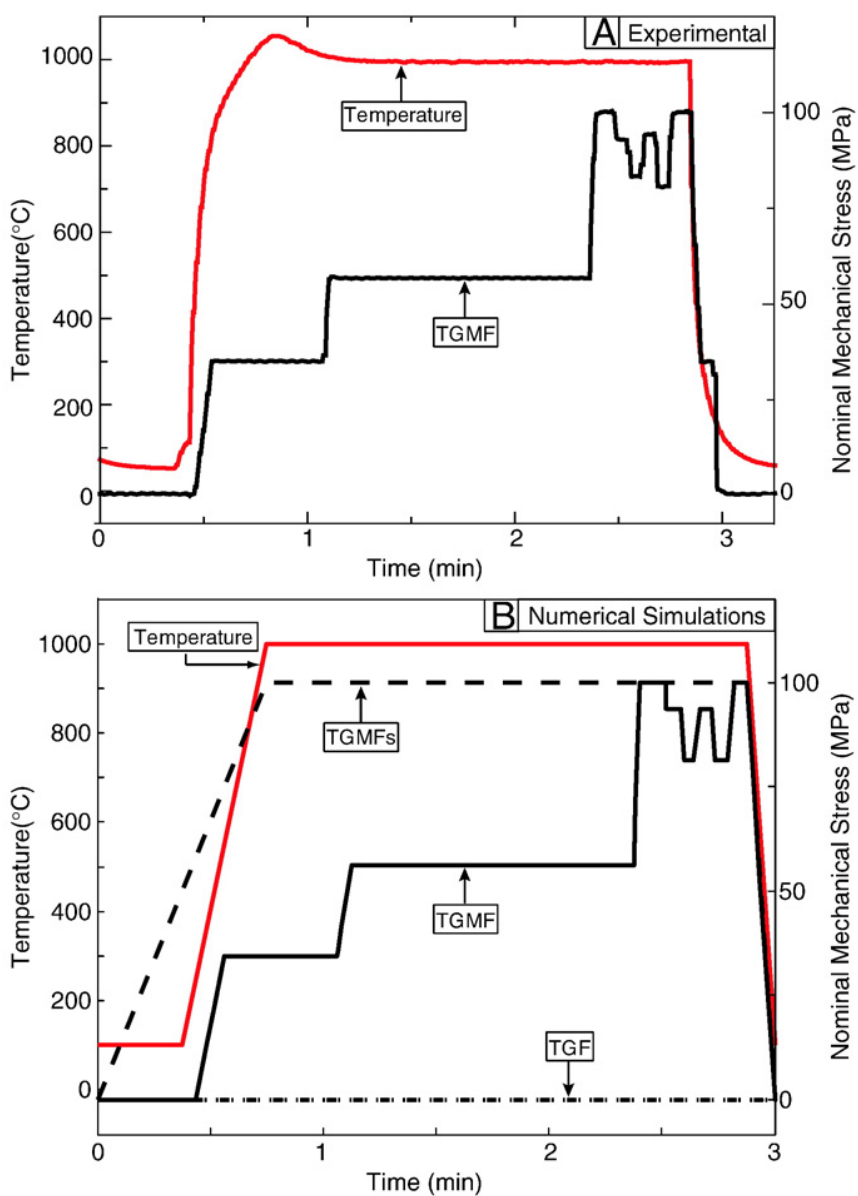

Fig. 2. TGMF cycle showing the mechanical load (in terms of nominal mechanical stress) and surface temperature. (A) Experimental TGMF and (B) Simulated thermomechanical loading including TGMF, $\mathrm{TGMF}_{\mathrm{s}}$ and TGF.

appear as cracks aligned in the bond coat perpendicular to the imposed mechanical load [6-8]. The key feature of the crack is that the crack extends through the top coat and the TGO, and bifurcates in the bond coat to advance parallel to the TGO. The bond coat part of the crack appears as cavities underneath the TGO, Fig. 3 . The cracks have a length in the circumferential direction of $0.5-2 \mathrm{~mm}$ and their width is 20 to $50 \mu \mathrm{m}$ after 500 TGMF cycles [8]. The cracks appear shallow and are located within the aluminum depleted zone of the bond coat [7,8]. After 1000 TGMF cycles these cracks were significantly larger and more distinct (Fig. 3). The length of the cracks in the circumferential direction extends up to $5 \mathrm{~mm}$ and the width ranges from 50 to $200 \mu \mathrm{m}$ [8].

Only specimens with a top coat exhibit this class of cracks. In the experiments where the top coat was removed prior to pre-oxidation and TGMF testing, cracks in the TGO were observed after the TGMF test, but these cracks did not evolve into the cavity as shown in Fig. 3. Instead, the crack kinks into the TGO leading to local spallation of this layer. Moreover, the particular cracks considered in this work only appear when the specimens have been pre-heat treated at $1000{ }^{\circ} \mathrm{C}$ for 250 or $500 \mathrm{~h}$ before the TGMF testing was conducted, but do not appear in the specimens tested from as-coated conditions. In fact, the samples tested from as-coated condition did not indicate any failure initiations after 4000 cycles [6-8].

\section{Problem definition}

Based on the experimental observations, we believe that the crack first develops across the TGO, Fig. 3 [6-8]. As the TBC is subjected to continued loading, the crack propagates in two directions: into the top coat and into the bond coat. The top coat crack grows outwards, towards the surface. The bond coat crack kinks and grows parallel to the TGO-bond coat interface within the aluminum depleted zone. We believe that due to the depletion of aluminum the material properties in the bond coat close to the TGO are different from the properties away from this interface and that this property difference causes the crack to kink in the bond coat. The development of TGO cracks will be the focus of this work. The ensuing evolution will be presented in a later study.

For through-the-thickness cracks to develop in the TGO, tensile stresses are needed. Thus, if we can establish how tensile stresses evolve in the TGO we can explain how the crack may have appeared. However, under normal conditions the TGO is typically subjected to large compressive stresses:

At high temperatures, a compressive stress evolve ( $<1 \mathrm{GPa}$ ), which is associated with the growth of the TGO and commonly referred to as the growth stress $[1,10]$. The growth mechanism of the TGO is governed by the aluminum in the bond coat that is converted into $\alpha$ $\mathrm{Al}_{2} \mathrm{O}_{3}$ [1]. When the alumina is formed, the TGO grows both thicker and longer with some growth occurring at the grain boundaries [1014]. The TGO is confined by the bond coat and the top coat. Consequently, the lengthening growth in the grain boundaries is constrained, resulting in a compressive growth stress in the TGO. One well established consequence of the compressive TGO stresses is that these can cause the TGO to be unstable against out-of-plane displacements ("surface instabilities") for some systems $[1,10,12,15,16]$. However, this particular TBC system does not exhibit these types of displacement instabilities when the top coat is present [16]. The growth stress at high temperature is limited due to creep properties of primarily the TGO but also the bond coat.

When cooling to ambient temperatures, compressive stresses develop in the TGO due to thermal expansion misfit between the TGO, the substrate, and the bond coat. This mismatch stress combined with the TGO growth stress is typically in the range of 3 to $6 \mathrm{GPa}$ [1,2,10,11,16-19].

In the TGMF load cycle, an axial tensile force is applied at high temperature. Can this tensile force overcome the intrinsic compressive TGO stress? We note that it is not possible that tensile stresses develop at ambient temperature for the TGMF load cycle, since the axial tensile force is only applied at elevated temperatures. Therefore, we will investigate if the axial tensile force applied at high temperatures in the
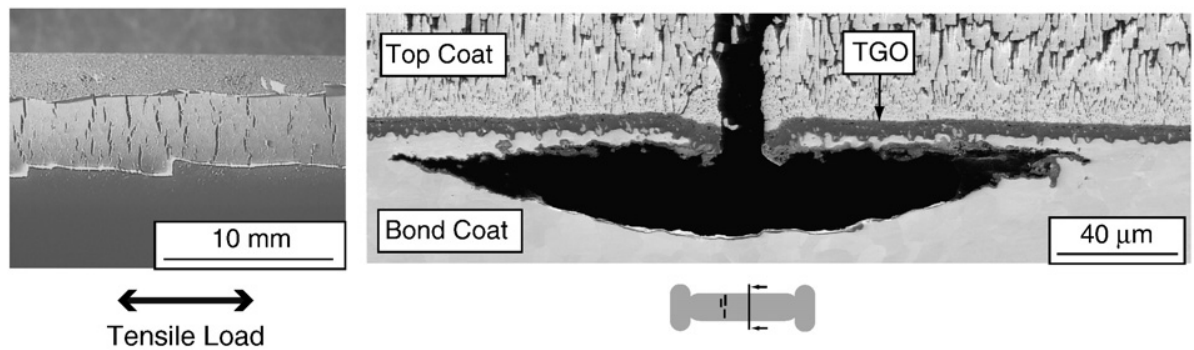

Fig. 3. Typical defects observed after 1000 TGMF cycles. 


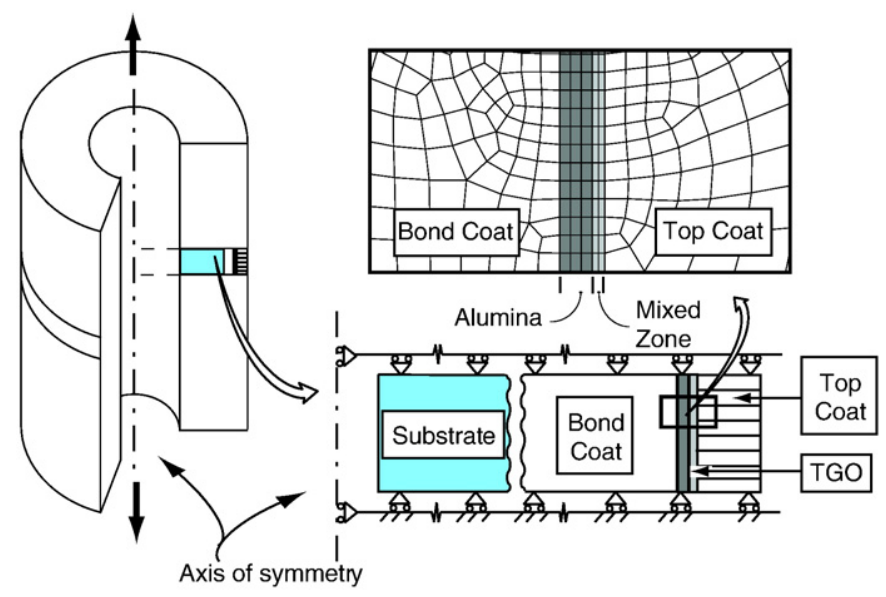

Fig. 4. Schematic of the axi-symmetric model implemented.

TGMF cycle can overcome the high temperature compressive TGO growth stress.

As previously noted, the cracks of interest do not appear in the specimens tested directly from as-coated conditions. Thus, the failure scenario must be associated with the differences between aged and as-coated TBCs. The most apparent difference is that as-coated TBCs have a significantly thinner TGO than the aged TGO $(0.3 \mu \mathrm{m}$ and $5 \mu \mathrm{m}$, respectively, before TGMF testing). The growth rate is significantly higher for the as-coated TBC, with the growth rate of the TGO typically described by a parabolic law $[1,4,5]$. Moreover, the as-coated TGO is primarily composed of a layer consisting of combination of alumina and zirconia ("mixed zone"), whereas the TGO in the aged specimens is composed of two dominant layers: a mixed zone (with almost constant thickness) and an alumina layer [4].

When the TGO forms and grows, the grain size of the TGO grows from small grains (less than $0.1 \mu \mathrm{m}$ ) to large grains (up to $2.5 \mu \mathrm{m}$ ) [14,20-22]. Rösler et al. [21] showed that the creep response changes with grain size of TGO formed by $\alpha$-alumina. There is a limited amount of data for TGO properties, in particular at high temperature properties. However, based on work by Evans et al. [23] and Rösler et al. [21] it is clear that the creep properties differ significantly for the grain sizes observed in the TGO. In addition, French et al. [24] studied the tensile creep behavior of the ceramic composite systems $\mathrm{Al}_{2} \mathrm{O}_{3}$ : c$\mathrm{ZrO}_{2}$ and $\mathrm{Al}_{2} \mathrm{O}_{3}: \mathrm{Y}_{3} \mathrm{Al}_{5} \mathrm{O}_{12}$. The creep data was modeled by the Norton Creep equation following data and calculations from $[22,24]$

$\dot{\varepsilon}=A d^{-p} \sigma^{n} e^{\left(\frac{-Q}{R T}\right)}$

where $\dot{\varepsilon}$ is the minimum strain rate, $A$ is a material constant, $d$ is the grain size, $p$ is the inverse grain size exponent, $Q$ is the apparent activation energy for creep, $\sigma$ is the applied stress, $n$ is the stress exponent, $R$ is the gas constant and $T$ is the absolute temperature. French et al. [24] found that in general the duplex microstructures (corresponding to the mixed zone in the current investigation) had lower creep rates than their single phase constituents ( $\alpha$-alumina).

We hypothesize that the response of the as-coated specimens are primarily differentiated from the aged specimens by the distinct grain sizes, chemical composition, creep response, and growth rate of the TGO. Consequently, we will investigate how the creep rate in the TGO influences the TGO stresses, and we will show that under certain conditions the TGO stresses may become tensile and can drive a crack through the TGO thickness of the heat treated specimens. The remainder of this paper will verify this hypothesis through finite element simulations utilizing the commercial program ABAQUS [25]. The numerical model will be described next and the results thereafter. As will be seen, the results obtained are consistent with our hypothesis.

\section{Numerical implementation}

\subsection{The finite element model}

Axi-symmetry is used to represent the test specimens (Fig. 4), where the model corresponds to a section of the experimental specimens far away from the grips. The inner and outer surfaces are free to move, and the temperature boundary conditions are applied on these surfaces. The model is constrained on its lower boundary against motion in the axial direction (corresponding to symmetry conditions). The upper boundary is prescribed so that all the coordinates are moving uniformly in the axial direction (corresponding to "continuous" conditions). The axial tensile stress is imposed on this surface. The length of the model in the axial direction $(0.1 \mathrm{~mm})$ is arbitrarily selected to avoid boundary effects, and there is no expected variation in the axial direction within this approximation (excluding local effects at the grips). Four-node bilinear coupled temperature-displacement elements (CAX4T) were used. Each model has approximately 1500 elements. A model with finer mesh yielded the same results, so we believe this is sufficient to capture the investigated results.

The models are initially assumed stress free at high temperature, corresponding to processing conditions. The thermo-mechanical loading applied on the models closely resembles the experimental procedure and is shown in Fig. 2B. The cycles have the same duration as in the experimental investigation. Up to 50 cycles are simulated. This is sufficient to show the overall evolution of the system. The growth strain in the model is imposed so that the TGO thickness obtained experimentally will be achieved in the numerical simulation. A temperature difference of $200{ }^{\circ} \mathrm{C}$ was used over the inner and outer boundary.

The temperature dependent material properties, including Young's modulus, Poisson ratio, thermal expansion, thermal conductivity, density, and heat capacity, used in the analysis are summarized in Table 2. For brevity, only the data at room and high temperature is shown in the table. In the analysis, temperature dependent material properties are considered, following Ref. [26]. The properties associated with time-dependent behavior at high temperature are discussed in Section 4.3.

\subsection{Aging and growth strain}

The studied defects did not occur for the specimens without preceding pre-heat treatment. Consequently, two models are created to capture the differences. The "as-coated model" corresponds to the specimens that were not subjected to pre-heat treatment. These specimens did not exhibit the defects investigated. Based on scanning electron microscopy (SEM) investigations, the initial TGO, mixed zone, is estimated to be $0.3 \mu \mathrm{m}$ thick [7,8]. Thus, the "as-coated model" consists of a single $0.3 \mu \mathrm{m}$ layer TGO, with the material properties based on the mix of alumina and zirconia, "mixed zone" in Table 3. This layer grows during thermal exposure. The "aged model" accounts for the specimens that were subjected to pre-heat treatment, where

Table 2

Material properties for the TBC materials at room temperature (RT) and $1000{ }^{\circ} \mathrm{C}(\mathrm{HT})$ [7,26].

\begin{tabular}{|c|c|c|c|c|c|c|c|c|}
\hline & \multicolumn{2}{|c|}{ Substrate } & \multicolumn{2}{|c|}{ Bond coat } & \multicolumn{2}{|l|}{ TGO } & \multicolumn{2}{|c|}{ Top coat } \\
\hline & $\overline{\mathrm{RT}}$ & HT & $\overline{\mathrm{RT}}$ & HT & $\overline{\mathrm{RT}}$ & HT & $\overline{\mathrm{RT}}$ & HT \\
\hline $\begin{array}{l}\text { Elastic modulus, } E \text {, radial or } \\
\text { isotropic [GPa] }\end{array}$ & 215 & 148 & 140 & 70 & 360 & 340 & 13 & 16 \\
\hline Elastic modulus, E, axial [GPa] & 120 & 80 & - & - & - & - & - & - \\
\hline Poisson ratio, $\nu$ & 0.3 & 0.3 & 0.322 & 0.351 & 0.24 & 0.24 & 0.22 & 0.28 \\
\hline $\begin{array}{l}\text { Coefficient of thermal expansion, } \\
\quad \alpha\left[10^{-6} 1 / \mathrm{K}\right]\end{array}$ & 11.5 & 18.8 & 8.6 & 16.6 & 6.0 & 8.7 & 9.0 & 11.5 \\
\hline Thermal conductivity, $\lambda[\mathrm{W} / \mathrm{mK}]$ & 15 & 30 & 8.7 & 27.5 & 23 & 5 & 1.88 & 1.60 \\
\hline Density, $\rho\left[\mathrm{g} / \mathrm{cm}^{3}\right]$ & 7.75 & 7.29 & 7.80 & 7.43 & 4.00 & 4.00 & 5.00 & 4.84 \\
\hline Heat capacity, $C_{p}[\mathrm{~J} / \mathrm{kgK}]$ & 400 & 580 & 390 & 700 & 769 & 1261 & 500 & 630 \\
\hline
\end{tabular}


Table 3

TGO creep law used in the FE analyses following Ref. [24].

\begin{tabular}{lllll}
\hline Creep law & Material & $P$ & $n$ & $\Delta H_{\mathrm{c}}[\mathrm{kJ} / \mathrm{mol}]$ \\
\hline$\dot{\varepsilon}=A d^{-p} \theta^{n} e^{\left(\frac{-Q}{R T}\right)}$ & Mixed zone & 2.2 & 1.8 & 633 \\
& Alumina & 2.2 & 1.7 & 453 \\
\hline
\end{tabular}

the particular defects under consideration were observed experimentally. The pre-oxidation generated a TGO of approximately $5 \mu \mathrm{m}$ thickness. The aged model is modeled with two sub-layers: (i) the layer "mixed zone" is modeled with constant thickness $1.4 \mu \mathrm{m}$, and (ii) the layer of alumina (with initial thickness $3.6 \mu \mathrm{m}$ ), which grows during thermal exposure.

As discussed previously, the TGO grows through both thickening and lengthening. The lengthening growth is manifested as a "growth strain." The growth strain is numerically simulated by imposing an eigen-strain (stress free strain) with the user subroutine UEXPAN [25]. Fig. 5 shows schematically how the eigen-strain corresponding to preheat treatment is imposed in the two models. Due to the constraints from the bond coat and top coat, the eigen-strain generates a compressive stress in the TGO. For the as-coated model, only a small lengthening growth strain is applied. This corresponds to the stresses that develop during processing. For the aged model, which includes pre-heat treatment, a larger lengthening strain is imposed during the simulated high temperature exposure, as shown in Fig. 5. Consequently, after the simulated pre-heat treatment the two models are differentiated by both the initial TGO thickness and the growth stress in the TGO when the thermo-mechanical load is imposed.

During the simulated TGMF testing following the pre-heat treatment, growth strain is applied in both the lengthening and thickening directions (during the intervals corresponding to high temperature exposure). Experimental observations indicate that the thickness of the TGO grows by following a parabolic law. To account for this, we use the coefficients suggested by Schulz et al. [5] for the simulations. The TGO of the as-coated specimens grows significantly faster than the TGO layer from the aged specimens, Fig. 6 .

In the as-coated model, the growth strain is imposed corresponding to a growth strain rate that would increase the thickness from $0.3 \mu \mathrm{m}$ to approximately $1.4 \mu \mathrm{m}$ in 500 TGMF cycles. In the aged model, the growth strain is only imposed in the lengthening direction in the mixed zone, whereas the growth strain rate in the $\alpha$-alumina layer corresponds to a thickness growth from $3.6 \mu \mathrm{m}$ to $3.8 \mu \mathrm{m}$ in 500 TGMF cycles. Both lengthening and thickening strains are imposed in the alumina layer. The lengthening strain for both models is taken as a tenth of the thickening strain $[10,16]$. Quantitative measurements of the lengthening strain compared to thickening strain are not available, and the ratio used is based on investigations where we compared experimental measured TGO stresses and varied the properties of the TGO along with the growth strain.

\subsection{Creep properties}

The models assume creep in both the bond coat and TGO. The creep properties are based on those found in Refs. [21,23,24]. The properties presented by Rösler et al. [21] and Evans et al. [23] appear to correspond to two distinct cases of TGO responses, almost instantaneous relaxation of stresses in Rösler et al. [21] versus almost elastic response in Evans et al. [23]. In both cases the properties correspond to pure $\alpha$-alumina $\left(\mathrm{Al}_{2} \mathrm{O}_{3}\right)$ [21,23]. As mentioned previously, the TGO is composed of $\alpha$-alumina but it also contains other constituents, such as oxides of zirconium, nickel. These constituents may change the materials properties. Consequently, the dependence of TGO creep on microstructure, temperature, and grain size was taken from French et al. [24] where various combinations of oxide constituents were considered. The power creep laws and their coefficients adopted in this work are summarized in Tables 3 and 4.

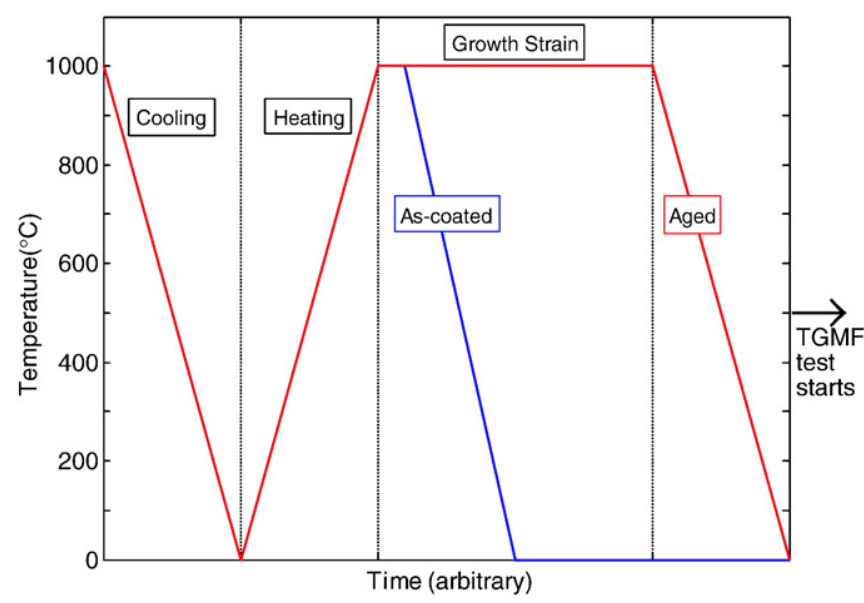

Fig. 5. Schematic of the initial FE-cycle, including the growth strain applied in order to account for the pre-heat treatment process.

Grain sizes of 0.1 and $1 \mu \mathrm{m}$ were considered for the material corresponding to the "mixed zone." For alumina, grain sizes of 0.1 , $0.5,1$, and $2 \mu \mathrm{m}$ were used. The constant $A$ was assumed to be $7.68 \mathrm{~N}^{-1.8} \mathrm{~mm}^{-5.6} \mathrm{~s}^{-1}$ for alumina and $6.37 \times 10^{5} \mathrm{~N}^{-1.7} \mathrm{~mm}^{-5.6} \mathrm{~s}^{-1}$ for the mixed zone. These constants were estimated by interpolating experimental data from French et al. [24]. The creep law was incorporated using the built-in routine CREEP [25] in ABAQUS.

To illustrate the creep response of the various creep laws, a finite element model of simple geometry was created in ABAQUS. This model consists of a hollow circular cylinder with inner and outer radius of $2 \mathrm{~mm}$ and $2.1203 \mathrm{~mm}$, respectively. It is composed of two layers: the inner layer (corresponding to the bond coat) is $120 \mu \mathrm{m}$ and the outer layer (corresponding to the TGO, using mixed zone and alumina properties) is $0.3 \mu \mathrm{m}$ thick. Two load steps are imposed: one static step, where a displacement is imposed linearly from 0 to $\delta_{\max }$ and a time-dependent step, where the material is allowed to relax following the creep laws imposed, keeping the displacement constant at $\delta_{\max }$.

\section{Results from numerical simulations}

\subsection{Overall response of the $T B C$}

We will first consider the distribution of the resultant axial stress over the cross section of the specimen due to thermo-mechanical

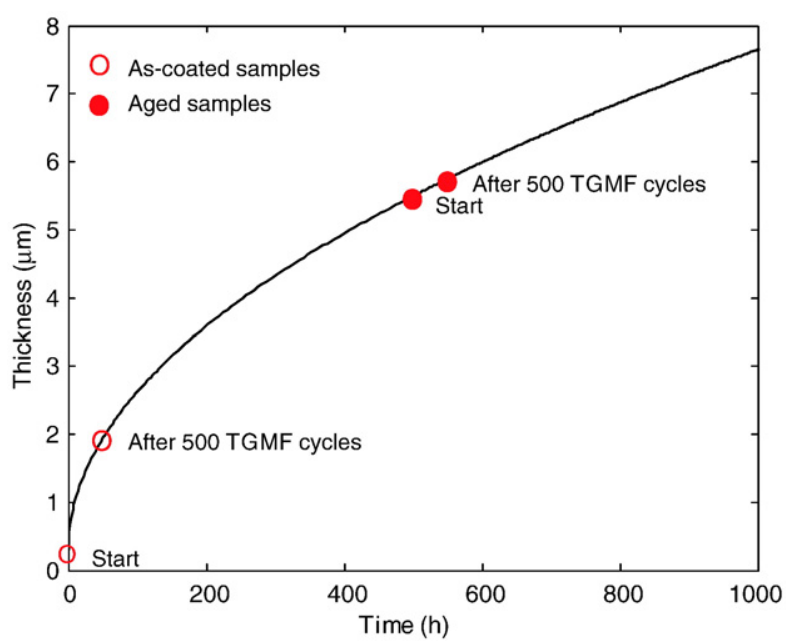

Fig. 6. Parabolic law used to predict the expected TGO thickness for as-coated and aged specimens: TGO thickness as a function of time. 
Table 4

Bond coat creep law used in the FE analyses following Ref. [23].

\begin{tabular}{lll}
\hline Creep law & $n$ & $B$ \\
\hline$\dot{\varepsilon}=\mathrm{B} \theta^{n}$ & 3 & $5.31 \mathrm{E}-9$ \\
\hline
\end{tabular}

loading at high temperature, with and without an axial tensile load, Fig. 7 (at maximum temperature). The results are extracted during the first cycle. In the following, the discussion is limited to the high temperature conditions, since we earlier concluded that the crack investigated must appear at high temperature and during mechanical loading. In this simulation, we assume that the TGO was $0.3 \mu \mathrm{m}$ thick, and the material properties were taken from Refs. [23,26].

The overall stress gradient is caused by the thermal gradient over the cylinder wall, and the stress discontinuities are due to the thermal mismatch between the constituents [16]. When an axial force is applied (TGMF), corresponding to the nominal stress $100 \mathrm{MPa}$, the results suggest that a significant part of this applied load is carried by the substrate. The stresses in the bond coat and top coat do not change significantly due to the applied load. Absent the mechanical load (TGF), the TGO exhibits a large compressive stress: the growth stress. When an axial tensile force is imposed, the magnitude of the resulting compressive stress is significantly reduced. However, in this case the imposed axial tensile force does not overcome the compressive stresses in the TGO.

\subsection{Response of the TGO}

The main objective of this investigation is to understand how an axial tensile stress can develop in the TGO. Thus, in the following, the discussion will be focused on the TGO stress for various material properties, loading and TGO growth conditions.

\subsubsection{Influence of creep properties}

For clarity of the presentation, the creep properties are visualized in a simplified model (described in Section 4.3) before discussing their influence in the as-coated and aged models. Fig. 8 shows the resultant axial stresses as a function of time for the investigated material properties (i.e., grain sizes) adopted from French et al. [24]. During the initial static step, the displacement is imposed linearly, and the material properties are assumed to be linear-elastic. After the initial static step, when the relaxation test is performed using time-

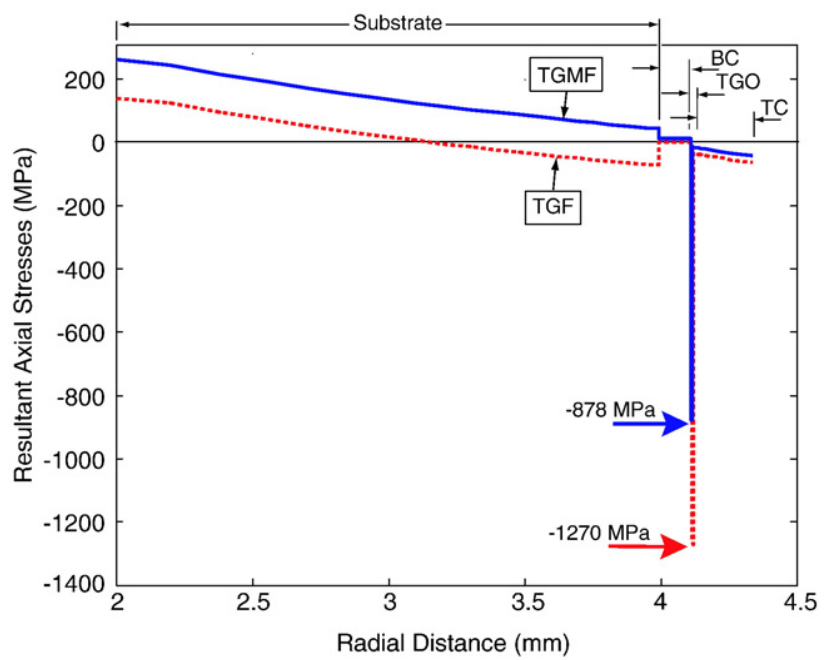

Fig. 7. Numerically obtained axial (in-plane) stress distribution over the cross section (as a function of the radial location) at high temperature without applied mechanical load (TGF) and for an imposed nominal axial stress of $100 \mathrm{MPa}$ (TGMF). (As-coated, during first full cycle.)

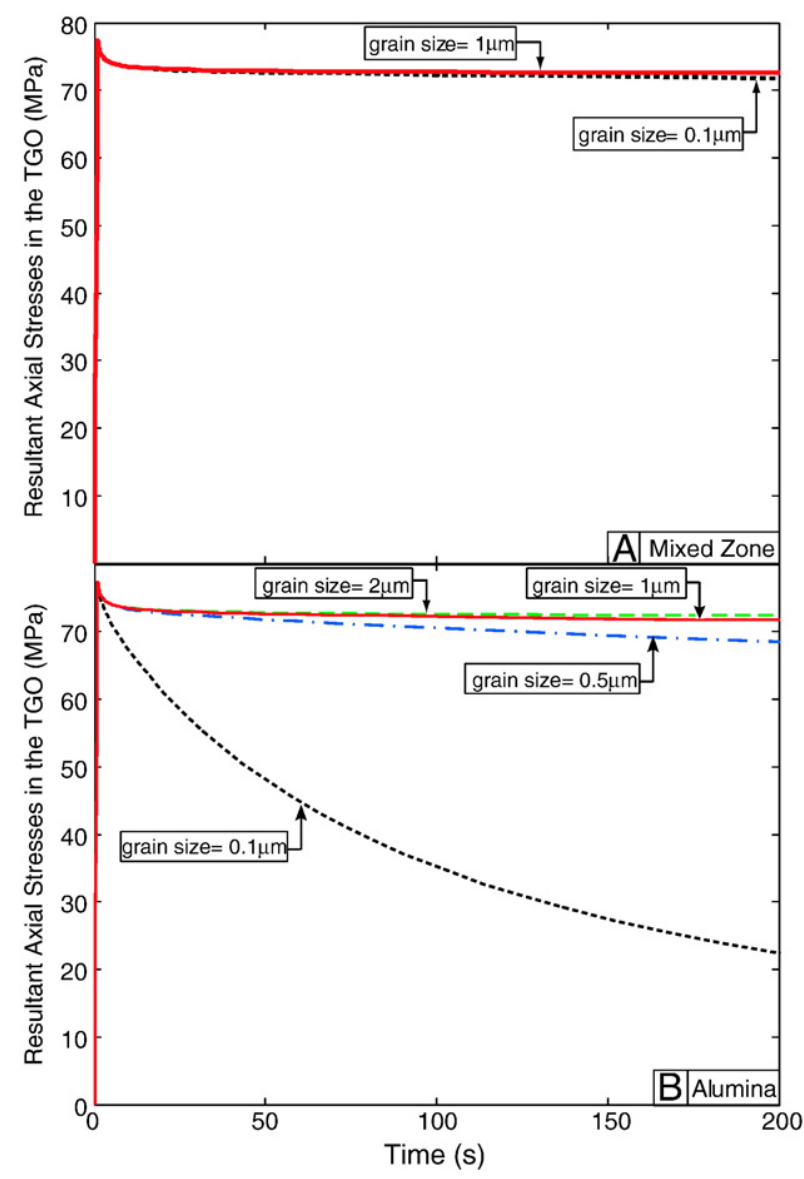

Fig. 8. Resultant axial (in-plane) stress in the TGO as a function of time during a relaxation simulation (simplified geometry), following properties from [24] for various grain sizes. (A) mixed zone (B) $\alpha$-alumina.

dependent properties, the alumina and the mixed zone show distinct creep/relaxation responses as the grain size is varied. The alumina relaxes faster than the mixed zone for grains smaller than $0.5 \mu \mathrm{m}$.

By assuming various combinations of grain sizes (and consequently creep responses) for the mixed zone and alumina [24], the influence of the TGO creep on the TGO stresses can be established. Figs. 9 and 10 show the resultant axial TGO stresses as a function of time in the as-coated (single layer, mixed zone) and aged (only showing the alumina layer) models for selected creep properties (i.e., grain sizes) as they evolve for the first three TGMF cycles. ${ }^{2}$ The results show that there is a direct correlation between the change in the applied axial force and the resultant axial stresses in the TGO ("TGO stresses") for all the cases considered (Figs. 9, 10). ${ }^{3}$ A competition between the imposed axial force and the growth strain can be also observed. In the first portion of the TGMF cycle, the applied load is less than $50 \mathrm{MPa}$, which is not enough to overcome the compressive stresses in the TGO due to the growth stresses. As the cycle progresses, the imposed axial load increases, diminishing the TGO growth stress effects and reducing the resultant compressive stresses in this layer.

\footnotetext{
2 The low temperature results have been truncated from the figures for simplicity since we are concerned with the stresses at high temperature only (where the studied defects are assumed to initiate as discussed previously). However, final spallation occurs during cooling.

${ }^{3}$ The local trend of evolution of the TGO stresses differs slightly between the first cycle and the following cycles. This is due to that the state of stress in the system changes significantly during the first cycle. Only small relative changes between consequential cycles are observed. In fact, for vanishing growth strain and creep, ensuing cycles would result in a cyclic steady state, commonly referred to shake-down.
} 


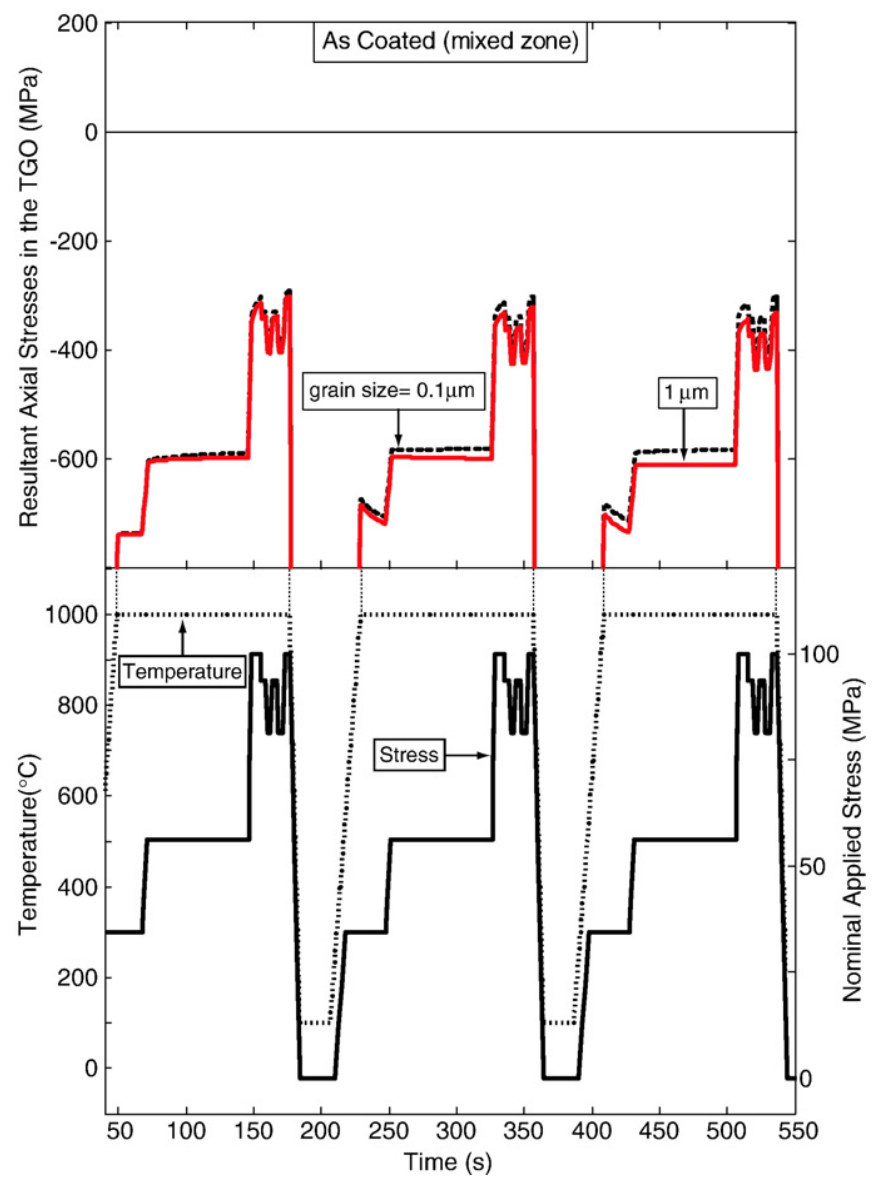

Fig. 9. Resultant axial (in-plane) stresses as a function of time during three TGMF cycles in the as-coated model (mixed zone) for grain sizes of 0.1 and $1 \mu \mathrm{m}$.

During the first cycles, the as-coated model (Fig. 9) show similar results for the two grain sizes considered. This may be expected, since the creep laws showed only minor differences in the response between the grain sizes investigated (Fig. 8). For the aged model, the grain sizes considered directly influence the TGO stresses. In general, a smaller grain size results in a faster creep response and less compressive stresses. Again, this sensitivity is expected based on the creep laws as illustrated in Fig. 8. For grain sizes less or equal to $1 \mu \mathrm{m}$, the TGO stresses relax in this layer after each load variation, Fig. 10. The stresses in the mixed zone are almost identical since the grain size was fixed for the aged model. For brevity, these results are not included.

Next, we consider the long term evolution of the axial TGO stresses, Fig. 11. The stress shown for each cycle is the resultant axial stress in the TGO just before cooling as a function of the number of cycles (TGMF loading). The competition of two effects-grain size (creep-relaxation) and growth strain-can be observed. Even though the grain size influences the stress evolution in the as-coated model (Fig. 11A), the stresses remain compressive after 50 TGMF cycles reaching a "cyclic steady state." The TGO in the as-coated model has a small initial thickness but has a high growth rate, especially at the beginning of the exposure at high temperature, Fig. 6. This high growth rate is reflected in the axial stress results in Fig. 11A, where initial high compressive stresses are achieved followed by a slow evolution. The grain size significantly influences the TGO stress (in the alumina layer) in the aged model (Fig. 11B). For grain sizes of $1 \mu \mathrm{m}$ or more, the resultant stresses are compressive and appear to stay compressive with cycling. In fact, the results indicate limited stress relaxation for these properties. However, for grain sizes of less than $1 \mu \mathrm{m}$, tensile stresses develop within the first TGMF cycles, reaching about 200 MPa. For both models, the evolution suggests that the relevant changes occur within the first TGMF cycles and that the structure reaches a cyclic steady state.

In summary, tensile stresses are more likely to develop in the alumina layer of the aged specimen, not only because the creep material properties of this layer are more favorable for stress relaxation, but also because of the slower TGO growth in the aged specimens.

\subsubsection{Influence of thermo-mechanical loading}

It is also important to understand the influence the mechanical loading has on the stress evolution. In particular, we are interested in establishing how the multiple stepwise changes in the axial force at high temperature influence the system. To investigate this, the models are subjected to the two alternative loading conditions shown in Fig. 2B. One load condition, the "simplified TGMF" loading $\left(\mathrm{TGMF}_{\mathrm{s}}\right)$, corresponds to a step load where the maximum axial mechanical nominal stress applied is $100 \mathrm{MPa}$ and is held constant during high temperature exposure. The second load condition, referred to as thermal gradient fatigue test (TGF), excludes the mechanical loading to explore the case of thermal gradient only.

Fig. 12 shows the resultant axial TGO stress as a function of time during the first three cycles for the as-coated and aged model (stress in the alumina layer). The results are for a fixed small grain size $(0.1 \mu \mathrm{m})$, and the three load conditions (TGMF, TGMF $\mathrm{s}_{\mathrm{s}}$ and TGF) are shown. Imposing an axial force on the as-coated model (Fig. 12A) decreases the magnitude of the resultant compressive TGO stresses compared to the TGF case. For the aged model, when imposing an axial tensile force, the TGO stresses trace that of the thermo-

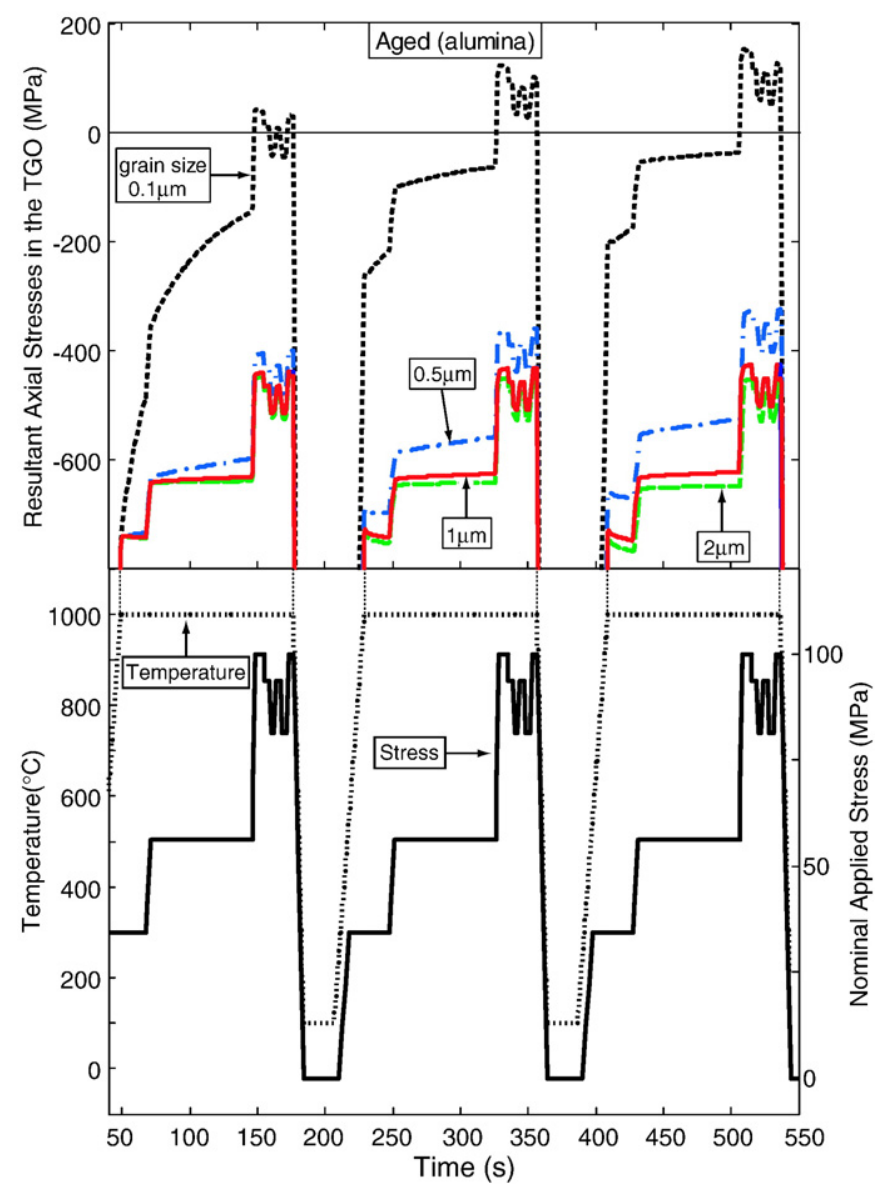

Fig. 10. Resultant axial (in-plane) stresses as a function of time during three TGMF cycles in aged model (in the alumina layer) for grain sizes of $0.1,0.5,1$ and $2 \mu \mathrm{m}$. 


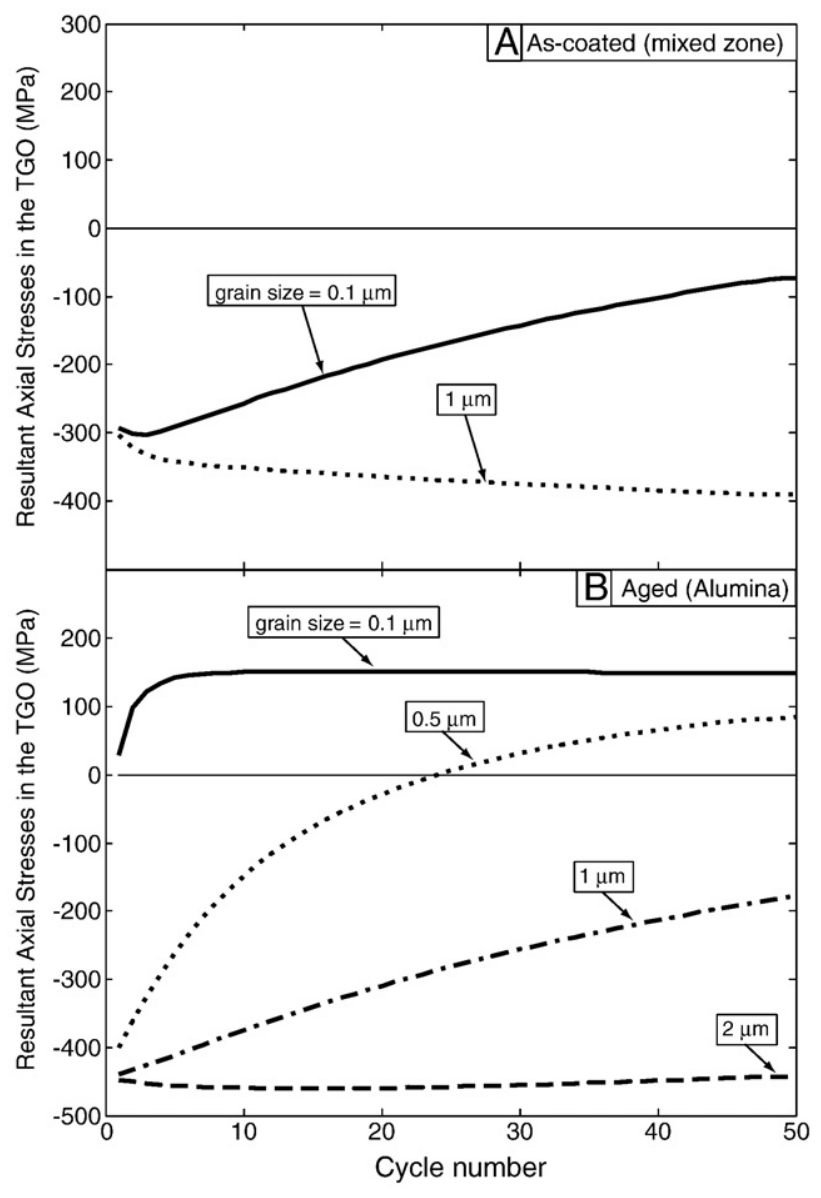

Fig. 11. The evolution of the resultant axial (in-plane) stresses as a function of load cycle for (A) as-coated model (mixed zone) for grain sizes of 0.1 and $1 \mu \mathrm{m}$, and (B) aged model (alumina layer) for grain sizes of $0.1,0.5,1$ and $2 \mu \mathrm{m}$. The stress corresponds to the maximum stress in each cycle.

mechanical load. However, tensile TGO stresses develop only for TGMF but not for $\mathrm{TGMF}_{\mathrm{s}}$ (Fig. 12B).

The overall TGO stress evolves in a similar manner for TGF and $\mathrm{TGMF}_{\mathrm{s}}$, suggesting that creep-relaxation dominates the response over the imposed mechanical load. However, for rapid changes in the imposed axial load (TGMF), the mechanical load dominates the resultant axial TGO stresses. Thus, it appears as the rapid change in the imposed axial load is critical for achieving resultant tensile stresses in the TGO. When considering the evolution for a larger number of cycles, Fig. 13B, TGMF with grain size of $0.1 \mu \mathrm{m}$ in the aged model is the only case that develops tensile stresses. Thus, the complex TGMF loading appears to be a key factor for tensile stresses to develop and consequently initiate the crack evolution considered.

\subsubsection{Influence of TGO growth}

The growth of the TGO also plays an important role on the TGO stress evolution. So far the growth stress was imposed so that the model predicts the experimentally obtained TGO thickness, following the parabolic law (Fig. 6). Varying the growth rate will elucidate the sensitivity of the growth strain rate in the stress distribution. The ascoated model has a very thin initial TGO that will grow at a faster rate compared to the aged model. The aged model will almost remain with a constant TGO thickness. Thus, we will only discuss the results for the as-coated model, where the changes are more substantial. The aged model follows the same tendency but with less distinction. Fig. 14A shows the general trend for the as-coated model for the cases with and without TGO thickness growth. When TGO growth is not considered, the TGO stresses are less compressive. However, the stresses remain compressive after 50 cycles.

The thickness of the TGO is directly related to the growth strain rate in that direction. But what is the influence of varying the lengthening stain on the axial stress results? To investigate this, the lengthening strain is increased and decreased by a factor of 10. Fig. 14B shows the TGO stress evolution of the different cases (for a fixed grain size). It can be seen that when the strain in the lengthening direction is decreased, the stresses become less compressive. For the material properties selected the change is minor. When the growth strain is increased, the results are more noticeable. In particular, increasing the lengthening strain will increase the magnitude of the compressive stresses.

\section{Concluding remarks}

We have investigated via numerical simulations a distinct set of cracks in thermal barrier coatings (TBCs). These cracks were observed after a proposed accelerated test scheme.

The accelerated test scheme consists of two parts. The specimens (hollow circular cylinder superalloy, with a TBC deposited on the outside surface) are first pre-heat treated in a separate furnace to develop a significant thermally grown oxide (TGO), and then tested in a thermo-mechanical cyclic test sequence where the mechanical load (axial tensile force) is synchronized with the thermal cycles. The thermo-mechanical loading is referred to as thermo-mechanical gradient fatigue (TGMF) test. The TGMF load sequence simulates an accelerated load cycle for a gas turbine engine. Selected specimens were tested directly in TGMF without the pre-heat treatment, for comparison.

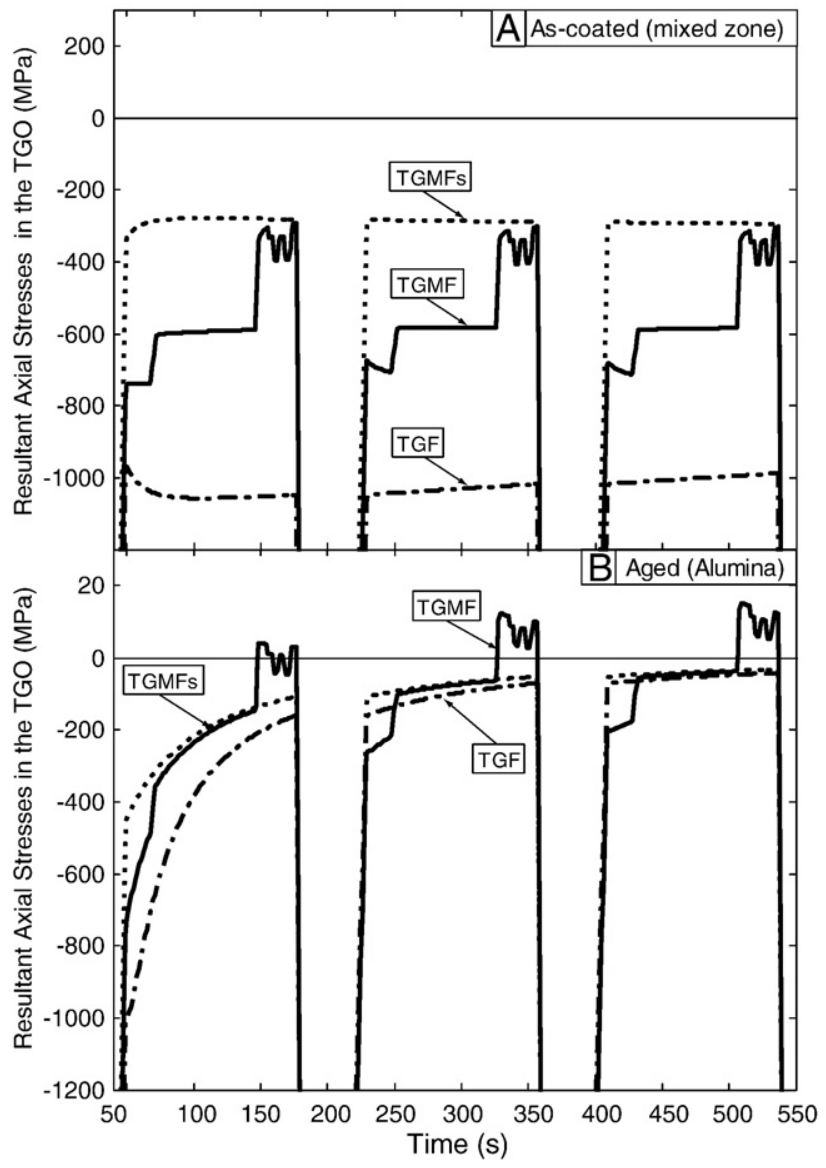

Fig. 12. Resultant axial (in-plane) stresses as a function of time during three TGMF cycles comparing TGMF, TGMF $\mathrm{s}_{\mathrm{s}}$ and TGF load sequences for grain size of $0.1 \mu \mathrm{m}$. (A) ascoated model (mixed zone), and (B) aged model (alumina layer). 


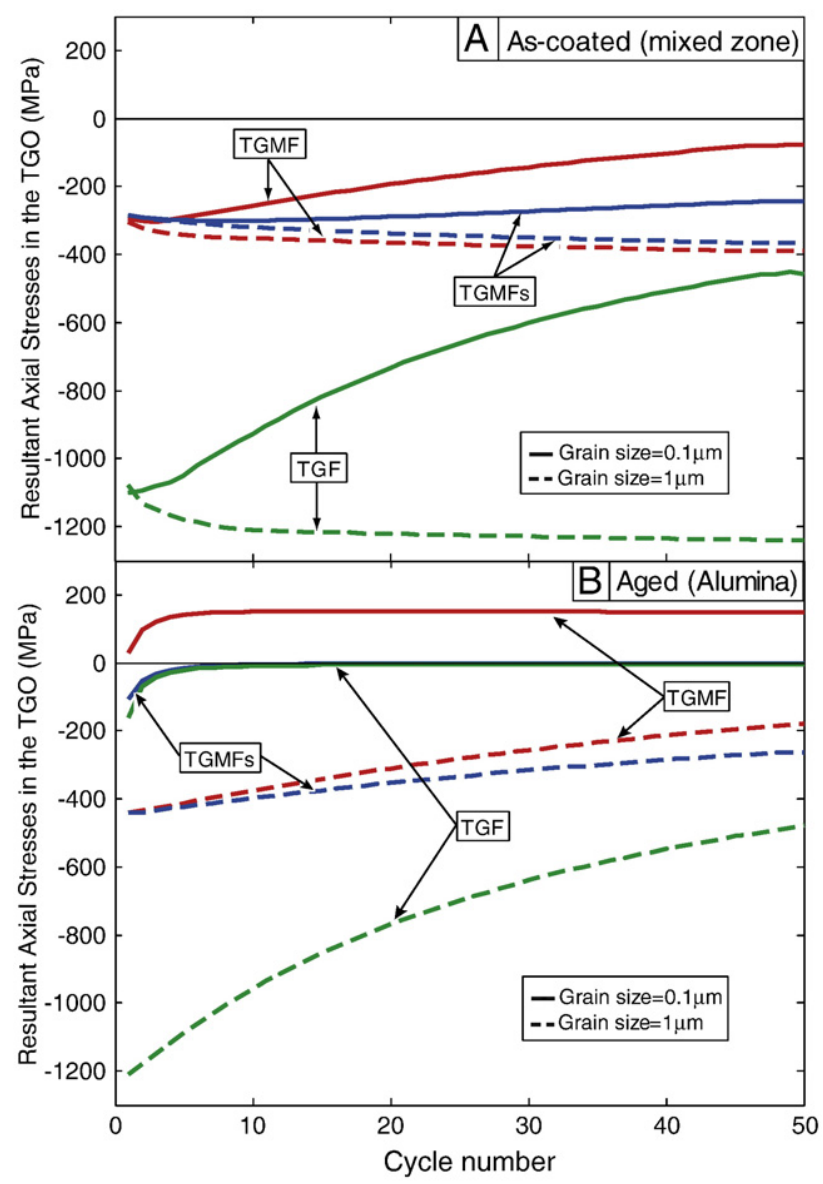

Fig. 13. The evolution of the resultant axial (in-plane) stresses as a function of load cycle comparing TGMF, TGMF and TGF, assuming grain sizes of 0.1 and $1 \mu \mathrm{m}(\mathrm{A})$ as-coated model (mixed zone layer), and (B) aged model (alumina layer). The stress corresponds to the maximum stress in each cycle.

The fatigue cracks first develop across the thickness of the TGO (based on image analysis presented in previous work). Thus, a sufficient in-plane tensile stress is needed in the TGO for these cracks to appear. However, a TGO is nominally in a compressive state of stress, due to the formation and the growth of the TGO, and due to the thermal mismatch with the other TBC constituents. The numerical investigation presented here focus on the development of tensile stresses. The results suggest that the intrinsic compressive mismatch stress can be overcome in the pre-heat treated specimens but not in the specimens tested in as coated conditions. There are several time and temperature dependent, non-linearly coupled properties that cause the cracks, including TGO growth stress, TGO structure, and load sequence. These three main characteristics all "compete" and contribute to the resultant axial (in-plane) TGO stress.

A key material characteristic is the growth stress in the TGO. This stress is compressive and directly associated with the formation and growth of the TGO. If no such stress existed, an external axial tensile load on a specimen would directly result in an in-plane tensile stress in the TGO. If this was the case, there would most likely not be a bifurcation of crack initiation between as-coated and pre-heat treated specimens.

The TGO is fundamentally different in the pre-heat treated specimens compared to the as-coated specimens. The TGO in the ascoated specimens is a mix of zirconia and alumina, referred to as the "mixed zone." The TGO in the aged specimens have two TGO layers, the "mixed zone" (next to the top coat) and a layer of primarily $\alpha$ alumina (next to the bond coat). These two layers have distinct material properties. In particular, small grains of $\alpha$-alumina exhibit relatively fast creep-relaxation compared to the mix of zirconia and alumina. By comparing various combinations of grain sizes (and therefore creep properties), our numerical results suggest that tensile stresses may develop during TGMF testing due to the relatively fast creep-relaxation of $\alpha$-alumina. We believe that the in-plane tensile stress in the TGO most likely develop early in the TGMF testing sequence, causing the through-the-thickness TGO crack to develop. The crack will then propagate into the top coat and bond coat, to form the characteristics feature. This propagation will be investigated in a later study. For the specimens that were tested in as-coated condition, the numerical simulations indicate that tensile stresses cannot develop, for the material properties considered.

The numerical simulations also show that the sequence, in which the tensile force is applied, is very important. The TGMF test consists of a rapidly changing axial tensile force, where the maximum tensile force is reached through a rapid force increase in the later half of the cycle. The tensile stress in the TGO develops when this rapid change to maximum tensile force occurs. The numerical model predicts that if the axial tensile force is applied to the maximum value directly instead of incrementally, in-plane TGO tensile stresses will not develop since the TGO has time to relax its stresses.

Thus, the development of the through-the-thickness TGO crack is caused by a combination and competition between TGO growth stress (by itself causing compressive in-plane TGO stresses in a TBC), externally applied tensile axial load (by itself causing tensile in-plane TGO stresses in a TBC) and the creep-relaxation of the TGO (wanting to reduce the magnitude of the stress in the TGO). Due to non-linear

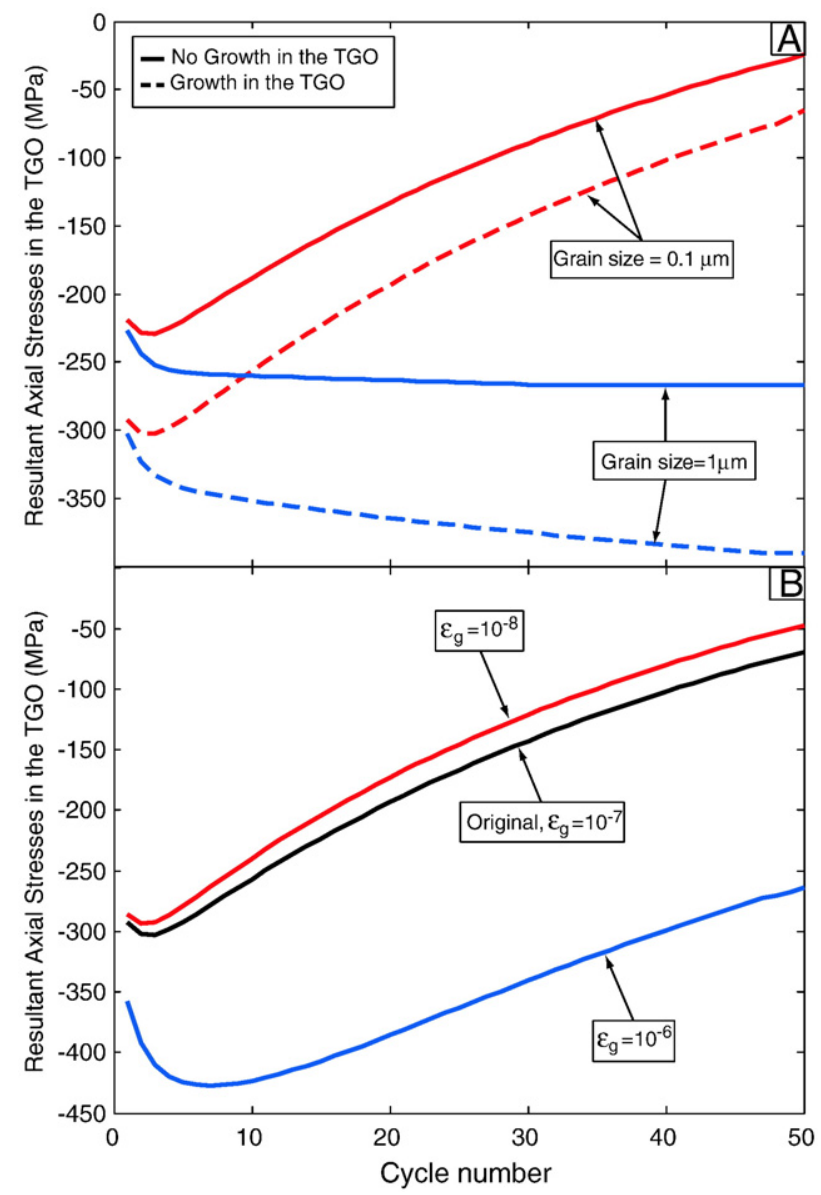

Fig. 14. The evolution of the resultant axial (in-plane) stresses as a function of load cycle for various assumed conditions of growth strain: (A) with and without TGO growth for the as-coated model assuming grain sizes of 0.1 and $1 \mu \mathrm{m}$, and (B) growth strain is varied in the lengthening direction (as-coated model, fixed grain size). The stress corresponds to the maximum stress in each cycle. 
and temperature dependent properties of a TBC, small variation of material parameters may enhance or suppress this class of cracks.

In all, this investigation shows that it is of high importance to carefully consider material properties and load sequences when evaluating failures of TBCs.

\section{Acknowledgments}

The authors would like to thank H. Mangers, K. Kröder, and J. Brien for processing the material system and B. Baufeld, C. Sick, and K. Mull for their contributions to the experimental data base. The financial support of the National Science Foundation (DMR-0710210) and the German Science Foundation (BA2304/2-1) are acknowledged.

\section{References}

[1] A.G. Evans, D.R. Mumm, J.W. Hutchinson, G.H. Meier, F.S. Pettit, Prog. Mater. Sci. 46 (2001) 505

[2] N.P. Padture, M. Gell, E.H. Jordan, Science 296 (2002) 280.

[3] M.J. Stiger, N.M. Yanar, R.W. Jackson, S.J. Laney, F.S. Pettit, G.H. Meier, A.S. Gandhi, C.G. Levi, Metall. Mater. Trans., A Phys. Metall. Mater. Sci. 38A (2007) 848

[4] W. Braue, U. Schulz, K. Fritscher, C. Leyens, R. Wirth, Mater. High Temp. 22 (2005) 393.

[5] U. Schulz, M. Menzebach, C. Leyens, Y.Q. Yang, Surf. Coat. Technol. 146 (2001) 117.

[6] M. Bartsch, B. Baufeld, M. Heinzelmann, A.M. Karlsson, S. Dalkilic, L. Chernova, Mater.wiss. Werkst.tech. 38 (2007) 712.

[7] B. Baufeld, M. Bartsch, S. Dalkilic, M. Heinzelmann, Surf. Coat. Technol. 200 (2005) 1282.
[8] M. Bartsch, B. Baufeld, S. Dalkilic, L. Chernova, M. Heinzelmann, Int. J. Fatigue 30 (2008) 211.

[9] M. Bartsch, G. Marci, K. Mull, C. Sick, Adv. Eng. Mater. 1 (1999) 127.

10] A.M. Karlsson, G. Evans, Acta Mater. 49 (2001) 1793.

[11] V.K. Tolpygo, J.R. Dryden, D.R. Clarke, Acta Mater. 46 (1998) 927.

[12] A.M. Karlsson, J.W. Hutchinson, A.G. Evans, Mater. Sci. Eng., A Struct. Mater.: Prop. Microstruct. Process. 351 (2003) 244.

[13] D.R. Clarke, Acta Mater. 51 (2003) 1393.

[14] I. Spitsberg, K. More, Mater. Sci. Eng., A Struct. Mater.: Prop. Microstruct. Process. 417 (2006) 322.

[15] J. Shi, S. Darzens, A.M. Karlsson, Mater. Sci. Eng., A Struct. Mater.: Prop. Microstruct. Process. 392 (2005) 301.

[16] J. Shi, A.M. Karlsson, B. Baufeld, M. Bartsch, Mater. Sci. Eng., A Struct. Mater.: Prop. Microstruct. Process. 434 (2006) 39.

[17] D.M. Lipkin, D.R. Clarke, Oxid. Met. 45 (1996) 267.

[18] M. Gell, K. Vaidyanathan, B. Barber, J. Cheng, E. Jordan, Metall. Mater. Trans., A Phys. Metall. Mater. Sci. 30 (1999) 427.

19] D.R. Mumm, A.G. Evans, I.T. Spitsberg, Acta Mater. 49 (2001) 2329.

[20] B.W. Veal, A.P. Paulikas, P.Y. Hou, Nat. Matters 5 (2006) 349.

[21] J. Rösler, M. Bäker, M. Volgmann, Acta Mater. 49 (2001) 3659.

[22] J. Schwarzer, D. Löhe, O. Vöhringer, Mater. Sci. Eng., A Struct. Mater.: Prop. Microstruct. Process. 387-389 (2004) 692.

[23] H.E. Evans, A. Strawbridge, R.A. Carolan, C.B. Ponton, Mater. Sci. Eng., A Struct. Mater.: Prop. Microstruct. Process. 225 (1997) 1.

[24] J.D. French, J.H. Zhao, M.P. Harmer, H.M. Chan, G.A. Miller, J. Am. Ceram. Soc. 77 (1994) 2857.

[25] A. I. ABAQUS 6.5 User's Manual, Pawtucket, Rhode Island (2004).

[26] M. Bartsch, DLR-Institute of Materials Research, German Aerospace Center (DLR), Linder Hoehe, D-51147 Cologne, Germany, 2006. 